\title{
Discussion on the Reform of Gutachtenstil Case Teaching of Penal Law*
}

\author{
Gang Luo \\ Law School \\ Xinjiang University \\ Urumchi, China 830047
}

\begin{abstract}
With the rapid development of legal theory and practice, higher and higher requirements have been raised for law students on their thinking ability, logical ability and case analysis ability are required more and more. In the reform of penal law teaching, it is necessary to deeply explore the new model and new way of law education, and introduce the method of gutachtenstil case teaching in time.
\end{abstract}

Keywords—penal law; gutachtenstil case teaching; reform

\section{INTRODUCTION}

With the deepening and prosperity of the study of law, the penal law teachers are constantly reforming and making innovations on their teaching methods. The ability to combine legal theory with positive law is a necessary quality for law students, yet, to some extent, traditional law school teaching methods cannot bridge the gap between legal theory and practical cases. How to train a legal person with strong thinking ability and rigorous logic to cross the gap between theory and practice poses a severe challenge to the traditional education mode of law school. Attention has been gradually paid to the popularization and development of case analysis training by the domestic community of legal education. As for case analysis, the method of "gutachtenstil case analysis" originating in Germany has become an important method of legal education in the country due to its strong system and advanced methods and has been gradually popularized.

\section{The CONNOTATION OF GUTACHTENSTIL CASE TEACHING OF PENAL LAW}

The so-called gutachtenstil case study refers to a case study method or pattern adopted by German law schools in teaching [1] [2]. The term "gutachtenstil" is the counterpart of adjudication and it is used to emphasize the feature of such a method that it assumes all possible cases, demonstrates them one by one, and comes to a conclusion. For every legal problem related when solving the cases, gutachtenstil requires students to follow the procedure of raising question-defining-making subsumption-reaching conclusion strictly. Raising question refers to put up the question to be argued; defining is set to define the concepts

*Fund Project: This paper is the research result of 2018 Research Project of Autonomous Region Undergraduate Education Reform "Construction of Analysis Library of Gutachtenstil Cases in the Penal Law Under the Background of 'Double First-rate'". in the question; making subsumption means to compare the facts of the case with the definition to determine whether the facts of the case meet the definition and thus meet the constitutive requirements; conclusion responds to the question at the beginning in the affirmative or negative way. This kind of job steps is actually an application of judicial syllogism, which is similar to solving mathematical equations in terms of form. The gutachtenstil case teaching of penal law is an inevitable product of the reform of penal law teaching. It is a new teaching method after case teaching method and clinical education method. The so-called case teaching method which originates from the case method in British and England, refers to a teaching method in which teachers, based on the concept of case teaching of common law system, adopt typical cases to bring students into real cases or virtual cases, enabling them to act as legal personnel and guiding them to study independently, according to the needs of teaching purpose and teaching content, so as to improve their ability to analyze and solve practical problems with careful design. The clinical legal education, refers to the practice in which the school provides opportunities for students to act as agents of real cases and contact with judicial organs and parties; students take specific steps to handle cases as main undertakers; and teachers give timely and necessary guidance for the problems students encounter in practice, so as to impart and train students' basic skills related to legal practice. Practice has proved that case teaching method cannot fully drive the interaction between teachers and students, and clinic education method lacks the soil for extensive cultivation in China. The best choice of penal law teaching is the organic combination of many teaching methods, such as case teaching method, heuristic teaching method and clinic teaching method. Gutachtenstil case teaching emphasizes putting the solution of all cases in one system. There is a clear "order list" inside the system, telling which article comes first and which next. Once students master this method, what they need to do is just to pin down the conditions according to specific details and subsume them one by one. Such practice that puts emphasis on systematic thinking not only greatly reduces the burden of thinking, but also represents clear process of argumentation with distinct structure. 


\section{The SignificAnCE OF THE GutACHTENSTIL CASE TEACHING METHOD}

\section{A. Improving Students' Mastery of Legal Interpretation Methods, Level of Reasoning by Use of Subsumtion Methods and Ability of Searching Legal Documents}

These three aspects are not only the teaching objectives that should be achieved in the construction of "double firstrate" universities, but also the three essential elements of excellent legal talents in practice.

\section{B. Promoting the Integration of Theory and Practice of the Penal Law}

For a long time, the undergraduate course penal law teaching pays too much attention to the theoretical knowledge, but neglects the legal practice. As an analytical method that takes into account both legal norms and scientific arguments, the gutachtenstil case teaching method encourage undergraduates to attach importance to the analysis of typical criminal law cases through the rigorous logic framework of academic papers to prevent theory from being divorced from practice.

\section{Enhancing the Perception of Legal Value and Mastering the Art of Balancing Different Values}

In the gutachtenstil case analysis, students must learn how to judge and choose between many conflicting legal norms, or between legal norms and theoretical theories in face of problems of penal law. This will greatly broaden the learning horizon of law students, so that they can not only follow the principle of expositor, but also reflect on the defects in legislation in the training with normative orientation as the primary and result orientation as the secondary. Treading through theories and norms, ideal and reality, students can have profounder understanding of the law, which is a fair and just method to settle disputes and balance the interests of all parties in society.

\section{THE CHARACTERISTIC OF THE GUTACHTENSTIL CASE TEACHING METHOD}

The reason why German law schools think highly of the gutachtenstil case study is that persistent gutachtenstil case study is very helpful to the development of the core competence that a legal personality needs, and contributes to the formation of the legal professional community.

\section{A. It Is Helpful to Understand and Systematize the Provisions of Positive Law}

The gutachtenstil case analysis emphasizes the solution of cases from the point of reality. The whole process of case analysis must be based on the specific legal provisions of the empirical law, not purely on the basis of legal theory or simple sense of justice. Although the German law schools allow carrying the articles of law in examination, to pass the examination, students have to be extremely familiar with the important law provisions; otherwise they will not be able to complete the answer within the prescribed time. Because of this, every student brings a separate edition of the Basic Law of the Federal Republic of Germany, German Civil Code, The German Penal Code, etc. or a compilation of the codes of various departments to class. It has thus become a unique and expressing sight that law school students walk in the campus with heavy compilations of legal provisions. In the process of constantly reading, the legal provisions are imperceptibly remembered, which is the fundamental reason why German professors can pick up legal provisions at random. In addition, in the process of solving cases, it is often necessary to apply a lot of closely related laws. For example, in the process of determining whether joint crime is constituted, it is necessary to understand and apply the relevant rules of joint crime. By answering several cases involving this issue, students can master the whole system of rules of joint crime skillfully. This will naturally make students form a network in mind to understand the provisions, which will virtually enhance the students' systematic thinking ability.

\section{B. It Is Helpful to Deepen the Understanding of Theoretical Knowledge and Systematize It}

Because the theory is relatively abstract, students often lack a real understanding of the theoretical knowledge learned in the theory class. Also, they only have smattering of why a certain theoretical dispute arises and it is hard for them to realize the intrinsic relevance with fragmented theoretical knowledge. As the gutachtenstil case analysis is a process of applying theories to living facts, students will naturally feel the role of theories in this process. They will realize the different meanings of different theories in individual cases, and accordingly their understanding of theoretical knowledge will not only be just superficial. In the process of solving a case, the coordination of different theoretical knowledge points is usually required, so students' understanding of theoretical knowledge is naturally systematic.

\section{The Gutachtenstil Case Study Is the Gymnastics of Legal Thinking, Which Contributes to the Improvement of the Legal Thinking Ability}

This is the most critical role of gutachtenstil case analysis. The key of legal education lies in cultivating legal thinking. And the so-called legal thinking refers to the interpretation of applicable law by following legal logic, thinking in line with value orientation and reasonable argumentation. The ability to interpret applicable law is undoubtedly the core of legal thinking ability, because it is an important criterion to distinguish people with and without systematic legal education. The process of solving a case with gutachtenstil is the process of applying the legal norm to a specific case. In this process, it is necessary to turn the eyes between norms and realities. Subsuming the realities to norms in the way of syllogism, it is necessary to master the legal methodology with legal interpretation as the core. When there is doubt about the provisions of positive law, reasonable legal interpretation is needed; in the place which the empirical law cannot reach, it is needed to make use of legal methodology to make rechtsfortbildung (law rebuilding), or to fill the legal loopholes. Through continuous training, the ability of legal 
thinking with the interpretation of applicable law as the core will naturally be greatly improved.

\section{It Helps to Improve the Input Capacity and Output Capacity}

The gutachtenstil case analysis highlights the process of argumentation. In order to make rational reasoning and decision, students need to search, sort out, read a lot of literature and even judicial decisions, and search for relevant laws and regulations and judicial interpretation. In this process, students' input ability will be greatly improved. Through the writing of case appraisal report, group discussion before class and teacher-student interaction discussion in class, students' output capacity of oral and written expression will naturally be enhanced.

\section{E. It Helps to Form a Real Legal Vocational Community}

Due to the need to stick to a specific format and analytical framework for gutachtenstil case analysis, law students will form a relatively fixed thinking framework after years of training. This makes different legal professionals in the future have a common knowledge background and thinking mode, so that the legal profession community can truly be formed. In view of its multiple functions mentioned above, the gutachtenstil case analysis is hailed as the pearl in the crown of German legal education.

\section{THE CONCRETE IMPLEMENTATION PLAN OF THE Gutachtenstil CASE TEACHING}

In the case ("案例") teaching method, "案" refers to specific litigation cases and "例" means an instance that is abstracted from a specific case and can be used to try similar cases [3]. Case teaching is a teaching method to improve students' decision-making ability and comprehensive quality. It can make students truly feel the practice of organization and management. From the perspective of ability cultivation, case teaching is helpful to cultivate students' professional operation consciousness and practical management ability. Each teaching case will give students certain information, leaving a series of questions. These questions have no standard answers for reference, and thus often require students to do in-depth, detailed thinking and exploration. Students, as subjects, are placed in the "case" situation and put forward specific measures by thinking and discussing the problems in the case. Case teaching trains the art of decision making of students and aims to train their ability to make decisions under unsatisfactory conditions. It emphasizes not the right answer, but the thinking process of coming to a conclusion, so as to cultivate students' divergent thinking.

\section{A. Selecting Cases Carefully}

After class, teachers can carefully select some examples suitable for students' discussion in class and closely combined with students' real life, so that students can discuss in class, which is the first step to arouse students' interest. Case teaching is an interactive teaching process that requires full preparation, careful reading and relevant background information before the course. This requires teachers to deliver case materials to students at least one day in advance, and ask students to discuss in groups and write down outlines of discussion.

\section{B. Creating the Problem Situation}

At the beginning of the class discussion, the teacher can set up some questions for the students, which can introduce the discussion of students.

\section{Class Discussion}

Students are asked to discuss over the designed questions, which is the key to case teaching and the climax of the whole teaching process. In this link, teachers must actively guide students and organize the activity. When there is a dispute between students, the teacher should not act as an arbiter, which does not contribute to reaching the goal of mutual inspiration, brainstorming.

\section{Results of Views Exchanging}

In this link, students are asked to make speeches in groups and exchange ideas. Through this link, students who have thought about it can have a meaningful exchange of ideas, so as to better stimulate their creative thinking.

\section{E. Explanation of Teachers}

After finishing the above steps, students are bound to have a series of questions, which requires teachers to summarize all kinds of views and make detailed explanations, so as to answer questions and deepen students' understanding of knowledge points.

\section{F. Comprehensive Assessment}

Finally, teachers should make effective evaluations of the whole classroom discussion and learning process. The evaluation can not only includes the teacher's summary and evaluation of the overall discussion of students, but also extends to the evaluation of the classroom discussion process, that is, the evaluation of the inter-group and intra-group cooperation, and the evaluation of the discussion of each member in each group. The evaluation report may be in the electronic form of relevant results or in other appropriate forms.

\section{CONCLUSION}

The penal law is a very important core course of law major and occupies a very important position in the legal education system. The teaching quality of this course is related to the realization of legal education goal and the process of legal construction in China. Therefore, it is of great significance to introduce and strengthen the teaching of gutachtenstil case teaching in classroom.

\section{REFERENCES}

[1] Liu Tianjun. Research on the Basic Theories of Case Teaching Method in Law Teaching. Journal of Hainan Radio \& TV University. 2005. 4. (in Chinese) 
[2] Li Xiaofei. Discussion of Clinical Legal Education. China Adult Education. 2007. 2. (in Chinese)

[3] Chen Xingliang. Compilation of Criminal Judicial Cases in China [M]. Beijing: China University of Political Science and Law Press, 1995. (in Chinese) 